\title{
Development and Testing of a Software Simulation Tool for Design of the Energy Management System in Elevators
}

\author{
Jorge Garcia*, Sarah Saeed*, Ramy Georgious*, Irene Pelaez*, \\ Bassam Mohamed*, Islam El Sayed*, Jose Mendiolagoitia ${ }^{\dagger}$ \\ * Electrical Engineering Dept., University of Oviedo. Gijon, Spain, garciajorge@uniovi.es \\ $\dagger$ Research Engineering Department, thyssenkrupp Elevator Innovation Center, Spain
}

\begin{abstract}
This work shows the development of a software tool that provides realistic operation power profiles in elevators for residential and public buildings applications. The implemented tool carries out a kinematic, dynamic and energetic analysis of the system, as a function of operational variables in the system. Therefore, the final load profile is a function of the most significant parameters in the operation of the elevator. These load profiles have several key applications, such as tuning the controllers of the control loops in the power converters, defining the power flow strategies, or sizing the power and energy ratings in energy storage system tied to the elevator system. The validity and applicability of the results from the simulator are verified through computer simulations, through a HIL (Hardware-In-theLoop) platform, and are finally validated by means of a full scale laboratory prototype of the system.
\end{abstract}

Index Terms-Vertical transportation, Energy storage, Hybrid Nanogrids, Elevators, HIL, Sustainable buildings.

\section{INTRODUCTION}

It is estimated that elevators transport over one billion people each day worldwide, accounting for a significant amount of the energy consumed on the average building. Previous generations of elevators accounted for an amount up to $10 \%$ of the energy consumed on the average building [1], [2]. Therefore, given the global interest towards fostering energyefficient solutions for building management, actions tending to enhance the performance of the elevator system will have a tremendous impact also on global energy consumption in transportation applications, thus being a major subject for research and development. This assertion is supported by the amount of research activities in the different lines related to this topic. In addition to the development of ubiquitous IoT technologies and intelligent management strategies, which are boosting the concept of energy management on smart buildings [3]-[6], two research lines are taking an increasing role in this regard. The first of these research lines is based on the development of software techniques that provide analysis and design tools to size and develop the elevator system aiming

This work has been partially supported by the Government of the Principality of Asturias, Spain, under Grant No. FC-GRUPIN-IDI/2018/000241 and SV-PA-17-RIS3-3. Also, it has been partially supported by the Innovation Development and Research Office (MEC), Spanish Government, under Research Grants ENE2016-77919, Project Conciliator, and by the European Union through ERFD Structural Funds (FEDER). to optimize the full performance [7]-[10]. These tools are usually focused on providing the design outputs of operational and design parameters in the system, parting from a configurable scheme of the elevator setup [11]-[13]. But there are also development platforms for designing the control of the elevator systems, that focus mainly on the system traffic analysis [14], [15]. The second research line covers the integration of energy storage systems at system level, to increase the energy efficiency of the overall system operation [3], [16]-[18].

The research presented in this digest joins the former two lines, by implementing a software tool to generate instantaneous power profiles demanded by the drive and ancillary systems in an elevator system. These profiles, generated as a function of operational parameters, are used to design the energy management strategy and the share of power between the grid and the energy system, and also to generate random daily patterns that allow for a sizing of the energy ratings of the storage system. It must be noticed that the output profiles generated by the proposed tool include a more realistic profile than the ones generated by the standard tools considered, which usually take into account an ideal state of the system. The information of real power profiles from elevators has been provided by the company thyssenkrupp Elevator Innovation Center, a division of thyssenkrupp Elevator, an international company that manufactures and operates elevator systems worldwide.

\section{AnAlysis of the Base CASE}

In order to derive valid conclusions, real information on the system under study must be available. For this purpose, actual load profiles in known operating modes of a given elevator, working with two different drives (conventional and regenerative drives), have been used. A summary of this residential base case is defined according to the parameters in Table I.

The two instantaneous power profiles, for both the conventional and the regenerative cases, considering a round trip of the empty elevators, are shown in Fig. 1a and 1b, respectively. In the conventional case, the machine drive burns any recovered mechanical energy to a resistor. However, in 
TABLE I: Parameters of the base case.

\begin{tabular}{cc}
\hline Payload & $450 \mathrm{Kg}$ \\
\hline Door Width & $800 \mathrm{~mm}$ \\
\hline Rated people & 6 \\
\hline Machine type & Gearless \\
\hline $\mathrm{N}$ floors & 5 \\
\hline Operation Category & 2 (VDI 4707) \\
\hline Floor Height & $3 \mathrm{~m}$ \\
\hline Total Trip & $15 \mathrm{~m}$ \\
\hline $\mathrm{N}$ dwells & 20 \\
\hline Deceleration Space & $18.25 \mathrm{~m}$ \\
\hline Cabin weight & $664 \mathrm{Kg}$ \\
\hline Counterweight Factor & 0.5 \\
\hline Rated Power & $3.4 \mathrm{~kW}$ \\
\hline Standby Power (std/regen) & $(56 \mathrm{~W} / 66 \mathrm{~W})$ \\
\hline Rated Speed & $1 \mathrm{~m} / \mathrm{s}$ \\
\hline Rated Current & $12 \mathrm{~A}$ \\
\hline
\end{tabular}

the regenerative case, that implements a bidirectional power converter with regenerative braking capability, the negative mechanical energy can be delivered back to the grid, and therefore, the power profile might reach negative instantaneous power values. The round trip starts with the elevator stopped in a given floor (the highest or the lowest one) with the doors open; then they are closed, the movement starts from the highest floor to the lowest floor (assuming the elevator was initially in the highest one) and then, the cabin stops. After that, the doors open, the system waits 10 seconds, then the doors close again and the cabin moves back to the highest floor. Lastly, the cabin stops and doors finally open again.

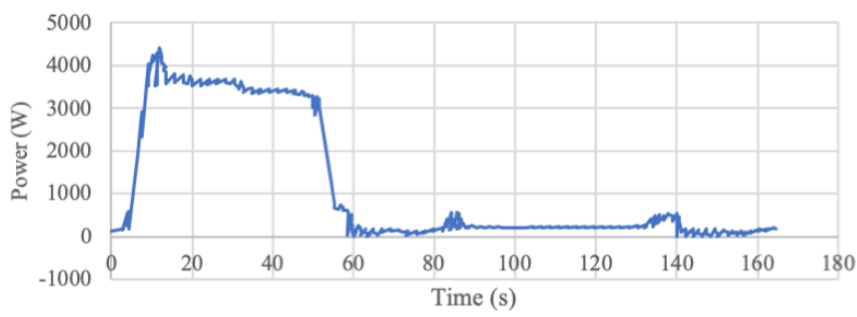

(a) Conventional Drive

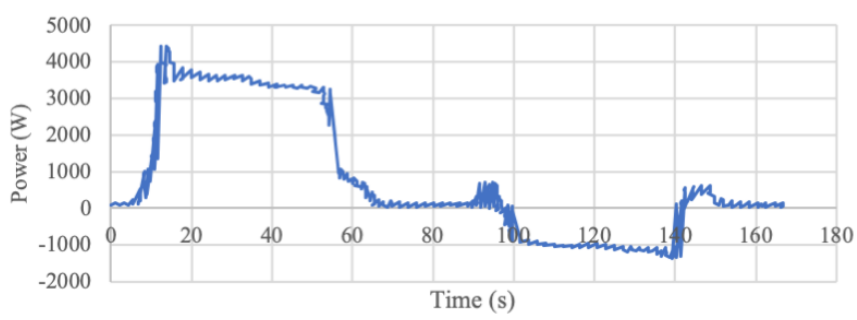

(b) Regenerative Drive

Fig. 1: Instantaneous power profiles of roundtrips with empty cabins.

A detailed analysis of this initial information was carried out, including a characterization of the mechanical system (kinematics and dynamics). For the study and implementation of the kinematic and dynamic analysis of the system, the basic motion equations in the elevator setup, which have been extensively covered in the technical literature, have been considered [13], [15], [16], [19].

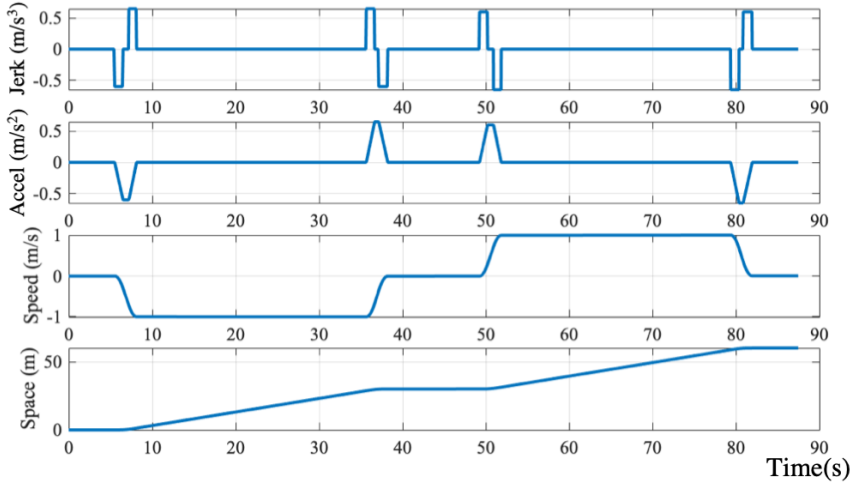

(a) Conventional Drive

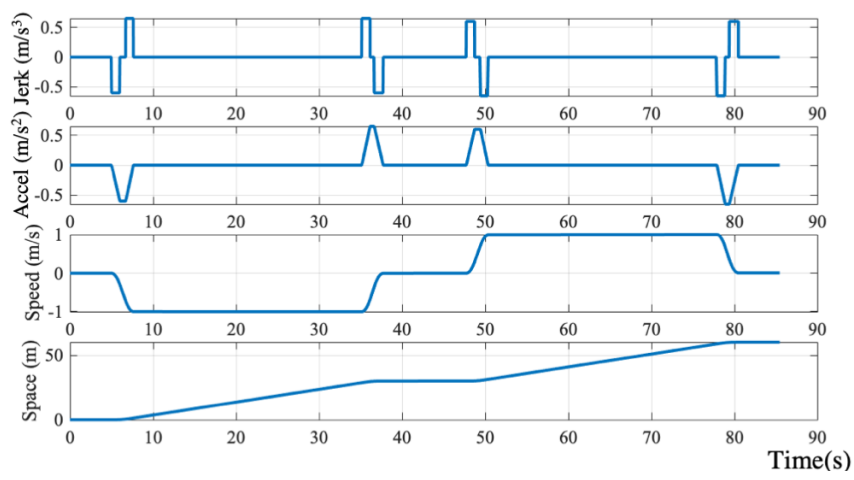

(b) Regenerative Drive

Fig. 2: Kinematic analysis of the movement of the elevators, for conventional and regenerative cases.

Figs. $2 \mathrm{a}$ and $2 \mathrm{~b}$ show the kinematics of the motion of the elevators. Also, the electrical and energetic analysis was integrated, in order to obtain the theoretical results that can be contrasted against the experimental results provided by the company. Figs. $3 \mathrm{a}$ and $3 \mathrm{~b}$ show the theoretical power profiles for the parameters described above, for both the conventional and the regenerative drives, respectively. For illustration purposes, these preliminary theoretical profiles have been plotted against the real profiles obtained from the company. It can be seen how the first approach is accurate; however, some error between the theoretical and the real values exist. These error plots are given in Fig. 4. As it can be seen, at some instant, the error has a significant effect. This error, mainly due to uncertainties in the definition of the system, cannot be accepted for the current study. Therefore, an analysis of these error waveforms were carried out, decomposing their values in the different stages of the movement. After this study, the final profiles obtained from the simulator finally match the original profiles properly.

\section{Parametric Profile Generation}

After the profile generator is adjusted in order to generate accurate profiles in the base case, a parametric profile generation was implemented. It is considered that the elevator is in an initial floor, $F_{I}$, and that the cabin is requested from another 


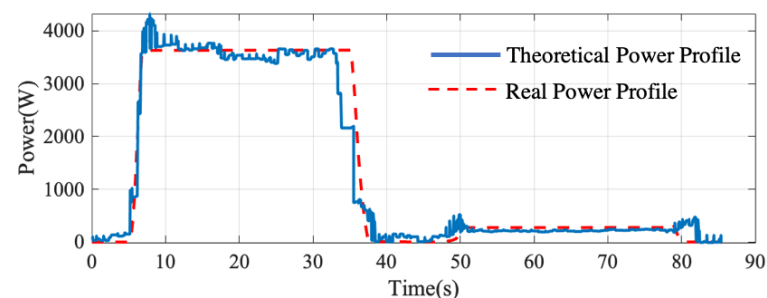

(a) Conventional Drive

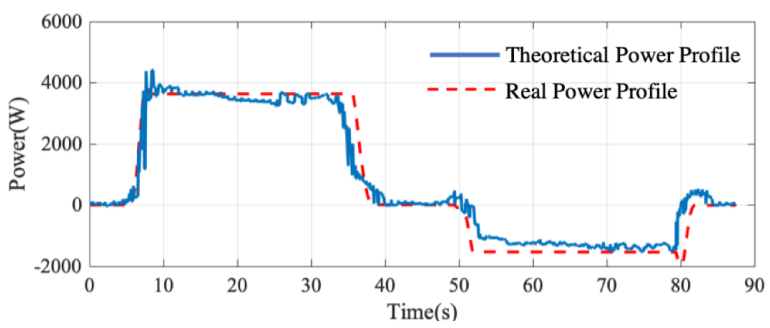

(b) Regenerative Drive

Fig. 3: Theoretical (red) vs. real (blue) instantaneous power profiles of roundtrips with empty cabins.

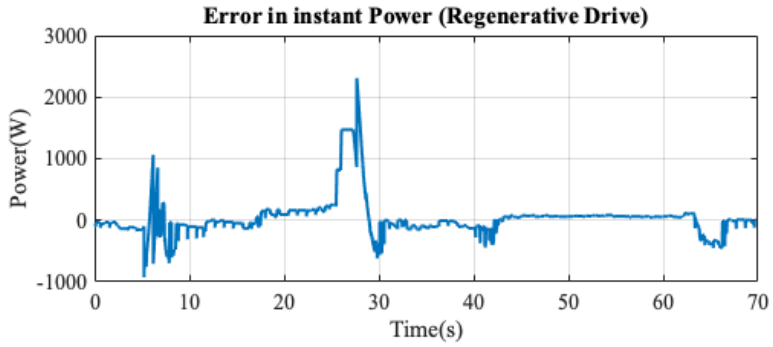

(a) Conventional Drive

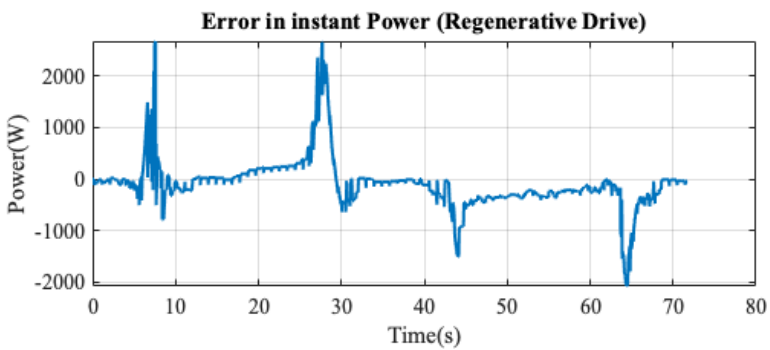

(b) Regenerative Drive

Fig. 4: Error between theoretical and real instantaneous power profiles of roundtrips with empty cabins.

floor, $F_{R}$. Once the passengers are on the cabin, it moves to a different destination floor, $F_{D}$. These parameters can be seen in Table II. It must be noticed that special situations, like $F_{I}$ being equal to $F_{R}$ (e.g. no initial travel, as the elevator is already in the requested floor), or the elevator carrying a payload also from $F_{I}$ to $F_{R}$ (e.g. consecutive travels carrying people from the requested floor to initial one) have also been considered.

The simulator thus provides realistic profiles considering any combination of the parameters ahead (provided that the physical constraints of the system are not overriden). For
TABLE II: Parameters of the profile simulator

\begin{tabular}{cc}
\hline Initial Floor & $F_{I}$ \\
\hline Floor Height & $h[\mathrm{~m}]$ \\
\hline Request Floor & $F_{R}$ \\
\hline Total No. Floors & $F$ \\
\hline Destination Floor & $F_{D}$ \\
\hline Nominal Speed & $V_{n o m}[\mathrm{~m} / \mathrm{s}]$ \\
\hline Nom. Accel./Decel. & $A_{N} / D_{N}$ \\
\hline Persons $F_{I}$ to $F_{R}$ & $N_{I 2 R}$ \\
\hline Nom. Jerk Ac./De. & $J_{A N} / J_{D N}\left[\mathrm{~m} / \mathrm{s}^{3}\right]$ \\
\hline Persons $F_{R}$ to $F_{D}$ & $N_{R 2 D}$ \\
\hline Cabin Weight & $W_{C}[\mathrm{~kg}]$ \\
\hline Counterweight Factor & $F_{C}$ \\
\hline Max. Payload & $W_{P}[\mathrm{~kg}]$ \\
\hline Max. number of People & $N_{\max }$ \\
\hline Mech. to Elec. Efficiency & $\eta$
\end{tabular}

demonstration purposes, Fig. 5 shows several random combinations of travels, keeping setup and kinematic parameters constant, but varying number of floors of the trips and number of passengers traveling. The information coming from the

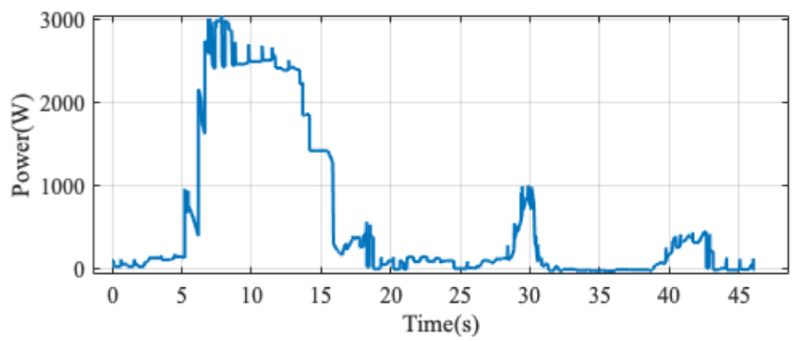

(a) Conventional drive, $F_{I}=5, F_{R}=3, F_{D}=1 N_{I 2 R}=2, N_{R 2 D}=5$.

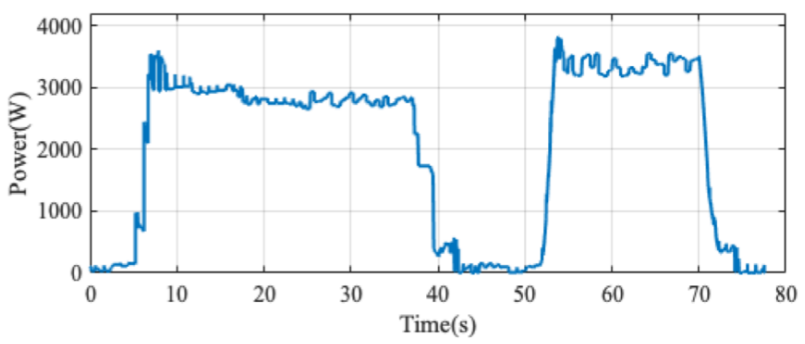

(b) Conventional drive, $F_{I}=-1, F_{R}=7, F_{D}=3 N_{I 2 R}=6, N_{R 2 D}=0$.

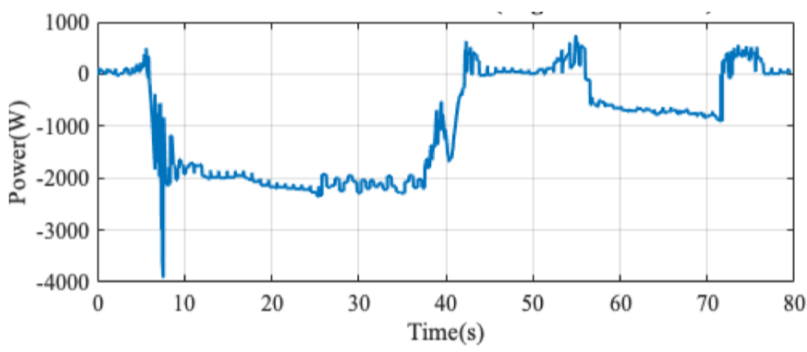

(c) Regenerative drive, $F_{I}=-1, F_{R}=7, F_{D}=3 N_{I 2 R}=0, N_{R 2 D}=6$.

Fig. 5: Power profiles obtained from the simulator for different conditions and parameters of operation.

simulator can be exported at different sampling rates in the most common file formats (*.csv, *.txt, etc.), in order to be processed for different purposes. 
IV. Structure of the Software Tool

Fig. 6 shows a basic diagram of the implemented tool. The

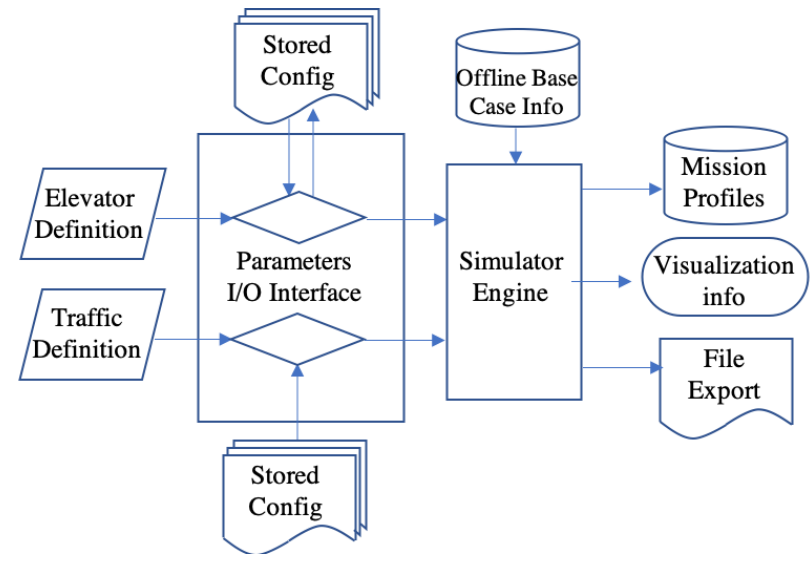

Fig. 6: Diagram of the software tool implemented.

definition of the physical parameters of the elevator can be entered either manually or considering specific configuration files. The information to enter is basically the one in Table I, but including more detailed aspects. In the same manner, the definition of the traffic and trajectory in a single trip (Table II) can also be included either manually or from a specific file. The information is processed and parsed, and sent to the simulation engine. This block generates the time arrays with the kinematic and energetic variables, considering the constraints selected by the user. On top of that, the tool takes information from an off-line database, and processes it in order to include the non-ideal behavior of the system. The simulation engine then outputs the information visually on the screen, but it can also be exported to different file formats. In next versions of the tool, the feature of exporting to a database will be included, so that the information can be used jointly with other building energy consumption patterns.

\section{VAlidation through Simulations AND EXPERIMENTAL RESULTS}

The power profiles coming from the simulator can be used as the load demand in computer simulations, in HIL platforms, or even in experimental setups that allow for the validation of power topologies, control schemes or energy management strategies in the elevator powertrain. This enables for an accurate design of the power electronics and control stages in the powertrain of the elevator, specially interesting in the case of integration of energy storage systems. Fig. 7 shows the structure of a converter used in a specific application to check the feasibility of including a hybrid energy storage system applied to the elevator case.

This system has been implemented in a HIL platform from Speedgoat, in order to design the control parameters that provide the desired power flow strategy. Table III shows the main parameters of the HIL Platform and of the laboratory setup.

Fig. 8a shows the HIL platform with the simulations of the full system. It must be remarked that one of the profiles

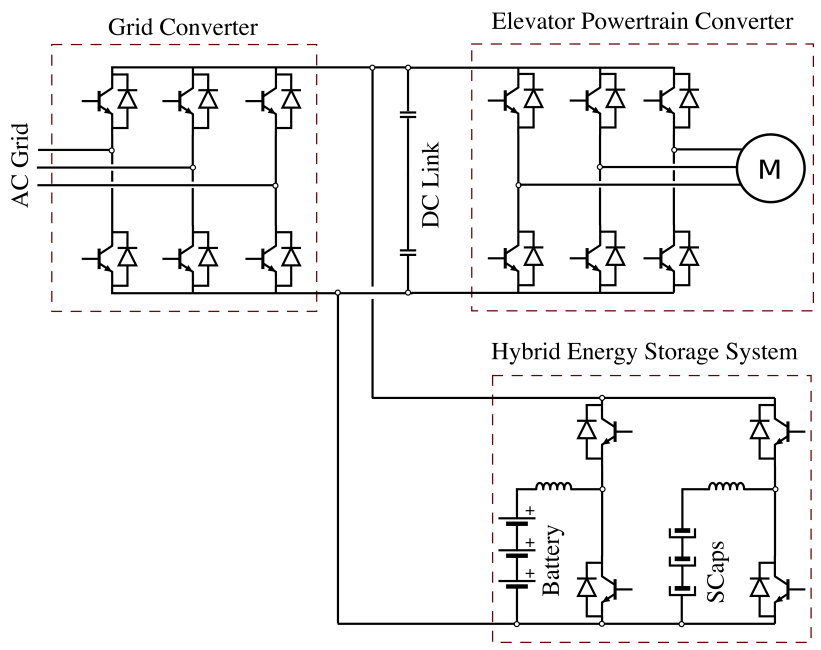

Fig. 7: Structure of the Power Electronic Converters in the System.

TABLE III: Parameters of the HIL Platform and Laboratory Setup

\begin{tabular}{cc}
\hline HIL Platform & RTM FPGA 100k \\
\hline HIL Manufacturer & Speedgoat \\
\hline HIL Processor & IntelCore i7 3770k 3.5 GHz \\
\hline HIL Memory & 4096MB \\
\hline HIL Main Drive & 250GB SSD \\
\hline Power Converter Topology & Back-to-Back Power Stack \\
\hline Power Converter Reference & MTL-B2B0040F12IXHE \\
\hline Power Converter Manufacturer & GUASCH Components \\
\hline Power Converter Ratings & 3Phase 460V ${ }_{R M} / 25 \mathrm{~A}$ \\
\hline Digital Controller Reference & TMS320F28335 DSC \\
\hline Digital Controller Manufacturer & Texas Instruments \\
\hline Battery Storage Device & Lithium-Ion Battery Rook P48 \\
\hline Battery Storage Manufacturer & Cegasa Portable Energy \\
\hline Battery Storage Ratings & 48V/100Ah \\
\hline Supercapacitor Device & SMA102V88FAF \\
\hline Supercapacitor Manufacturer & Skeleton Technologies \\
\hline Supercapacitor Ratings & 102V/ 88F \\
\hline
\end{tabular}

obtained from the developed profile generator is implemented as the elevator power command. Fig. 8b shows a capture of the instantaneous power waveforms in the main elements of the full system, for a given set of design parameters in the controllers.

Fig. 8c illustrates the developed $10 \mathrm{~kW}$ converter which interfaces the energy storage units in the hybrid system. This system is formed by a Li-Ion battery module of $48 \mathrm{~V}$ nominal voltage and 100Ah, along with a Battery Management System (BMS). A supercapacitor module is also integrated which has nominal ratings of $102 \mathrm{~V} / 88 \mathrm{~F}$. The experimental waveforms obtained from the non-regenerative load profile are presented in Fig. 9. It shows the DC-link voltage variations with the load profile, as well as the evolution of the grid current.

The experiments carried out include the validation of a series of random trips, through the comparison of the simulated profile vs. the actual waveforms in the laboratory setup.

Another important aspect of the generator is the ability to provide daily instantaneous power profiles of the elevator, con- 


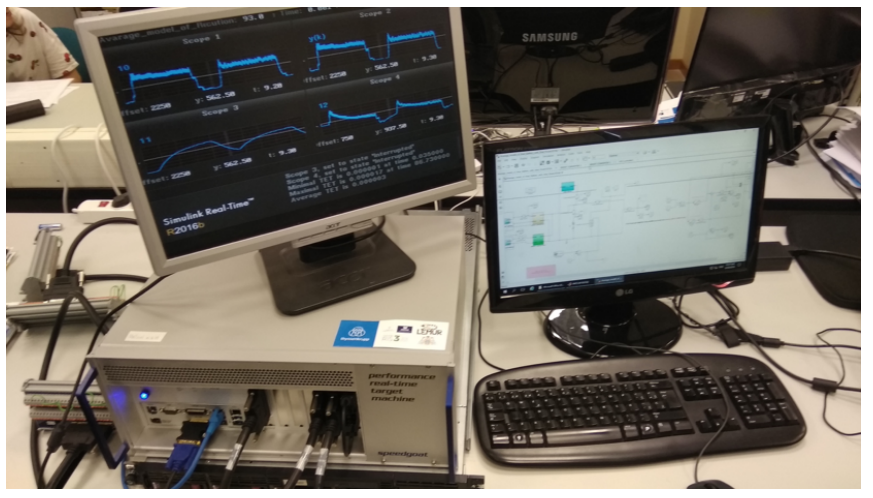

(a) HIL Platform processing the system.
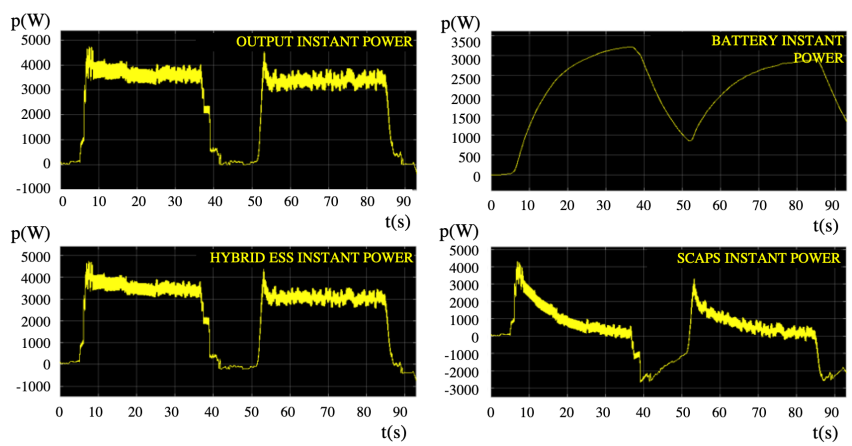

(b) Instantaneous power waveform in the HIL platform. From top to bottom left: Profile from simulator \& ref. for the energy storage system; right: ref. for battery \& for supercaps.
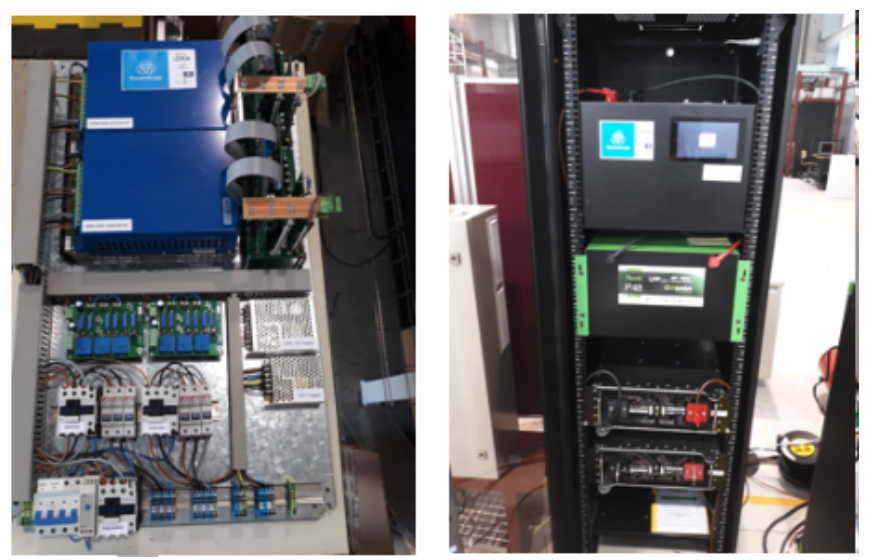

(c) Left: Setup of the converter and control for the system. Right: energy storage subsystem (up: BMS. center: Li-Ion Battery. down: Supercapacitor Modules).

Fig. 8: Application of the outputs of the software simulation tool to the experimental setup.

sidering stochastic usage patterns of the facility. The random profile generation feature has been implemented in the tool, taking into account information about categories of use and stochastic distribution of the travel patterns in residential or commercial buildings [20], [21]. These profiles are critical in order to evaluate the efficiency energy class of the system and possible optimization strategies (evaluation of the most convenient tariff, optimal size of the eventual storage and microgeneration systems, etc.). Fig. 10 shows one of such daily profiles, for a category use 4, considering the VDI 4707 regulations.
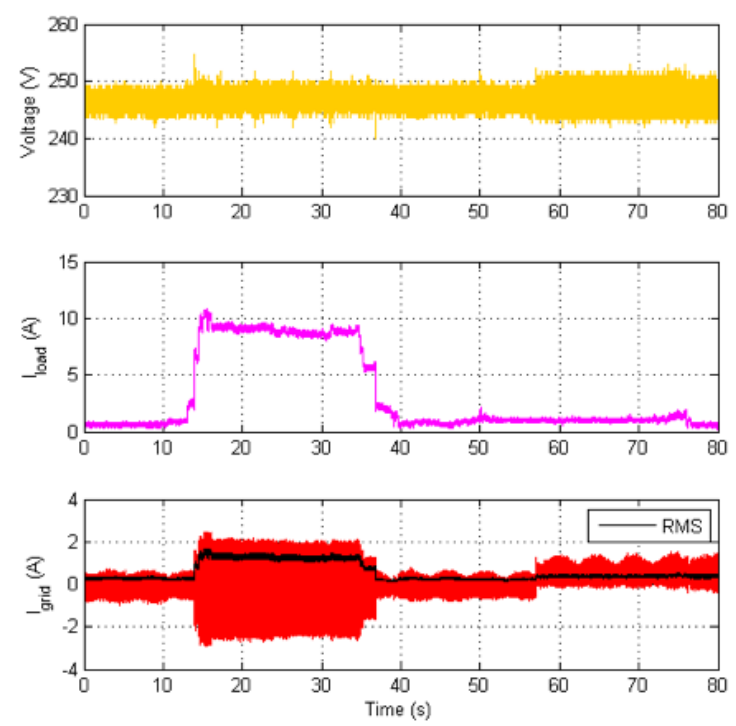

Fig. 9: Measured waveforms in prototype. Top: DC link $\mathrm{V}_{R M S}$. Center : Load current profile. Bottom:Grid current (phase)

\section{Conclusions}

A software tool that provides realistic operation power profiles in elevators for residential and public buildings applications has been presented. In addition to providing a kinematic, dynamic and energetic parametric analysis of the system, the tool is able to generate single trip profiles as well as daily power profiles. This is a key tool in critical design tasks such as dimensioning the power and energy ratings, control design, or definition of the power management strategies as well.

The applicability of the tool has been assessed through its integration into a HIL platform system as well as in a fullscale prototype of the elevator system, providing the reference signal for the load power.

\section{REFERENCES}

[1] J. Fisher, "Thyssenkrupp is the first to enable conversion of existing elevators into net-zero energy units through modernization," Press Release, https://www.thyssenkrupp-elevator.com, 2017.

[2] B. Urban and K. Roth, "Demonstrating a Net-Zero Solar Energy Elevator in a Boston Office Building," Fraunhofer USA Center for Sustainable Energy Systems, USA, Final Report 1, May 2016.

[3] E. Bilbao, P. Barrade, I. Etxeberria-Otadui, A. Rufer, S. Luri, and I. Gil, "Optimal Energy Management Strategy of an Improved Elevator With Energy Storage Capacity Based on Dynamic Programming," IEEE Transactions on Industry Applications, vol. 50, no. 2, pp. 1233-1244, March 2014.

[4] M. Manic, D. Wijayasekara, K. Amarasinghe, and J. J. RodriguezAndina, "Building Energy Management Systems: The Age of Intelligent and Adaptive Buildings," IEEE Industrial Electronics Magazine, vol. 10, no. 1, pp. 25-39, March 2016. 

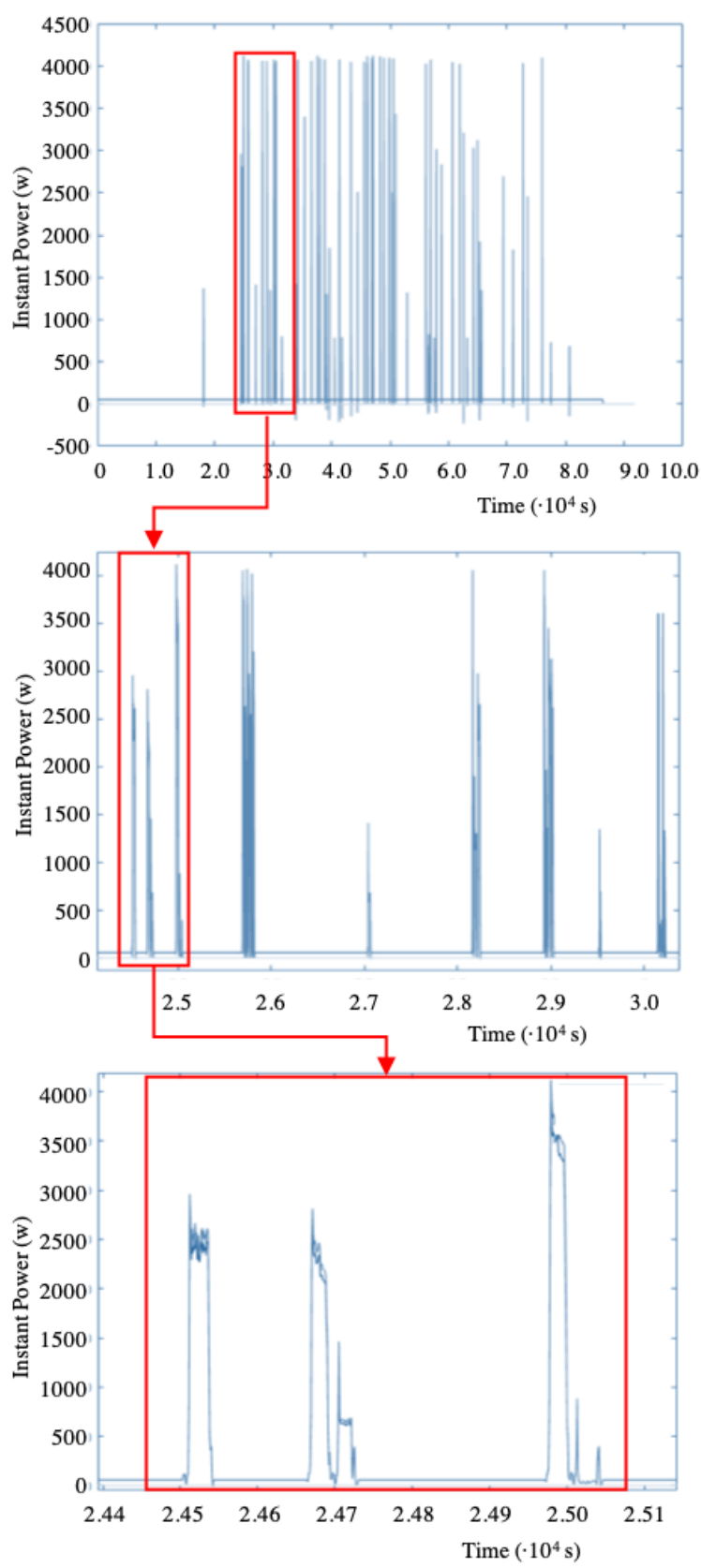

Fig. 10: Daily profile.
System," in Proceedings of the Power Conversion Conference-Osaka 2002 (Cat. No.02TH8579), vol. 2, April 2002, pp. 885-889 vol.2.

[9] N. Chaosangket, P. Sasithong, S. K. Wijayasekara, W. Asdornwised, L. Wuttisittikulkij, P. Vanichchanunt, and M. Saadi, "A Simulation Tool for Vertical Transportation Systems using Python," in 2018 5th International Conference on Business and Industrial Research (ICBIR), May 2018, pp. 270-275.

[10] H.-M. Ryu and S.-K. Sul, "Position Control for Direct Landing of Elevator Using Time-based Position Pattern Generation," in Conference Record of the 2002 IEEE Industry Applications Conference. 37th IAS Annual Meeting, vol. 1, Oct 2002, pp. 644-649 vol.1.

[11] "FineLIFT TM," Website,, 2019. [Online]. Available: https://www.4msa.com

[12] P. Cortes, J. Muuzuri, and L. Onieva, "Design and Analysis of a Tool for Planning and Simulating Dynamic Vertical Transport," SIMULATION, vol. 82, no. 4, pp. 255-274, 2006.

[13] L. Al-Sharif, R. Peters, and R. Smith, "Elevator Energy Simulation Model," IAEE Elevator Technology 14, 2004.

[14] R. D. Peters, "The Application of Simulation to Traffic Design and Dispatcher Testing," in The 3rd Lift Symposium on Lift and Escalator Technologies, Northampton, UK, vol. 1, Oct 2013.

[15] G. Barney and L. Al-Sharif, Elevator Traffic Handbook: Theory and Practice. Routledge, 2016.

[16] N. Jabbour and C. Mademlis, "Improved Control Strategy of a Supercapacitor-Based Energy Recovery System for Elevator Applications," IEEE Transactions on Power Electronics, vol. 31, no. 12, pp. 8398-8408, Dec 2016.

[17] A. Rufer and P. Barrade, "A supercapacitor-based energy-storage system for elevators with soft commutated interface," IEEE Transactions on Industry Applications, vol. 38, no. 5, pp. 1151-1159, Sep. 2002.

[18] N. Jabbour and C. Mademlis, "Supercapacitor-Based Energy Recovery System With Improved Power Control and Energy Management for Elevator Applications," IEEE Transactions on Power Electronics, vol. 32, no. 12, pp. 9389-9399, Dec 2017.

[19] R. D. Peters, "Ideal Lift Kinematics," in The International Congress on Vertical Transportation Technologies, ELEVCON HONG KONG, vol. 1, Oct 1995.

[20] H. Hakala, M. Siikonen, T. Tyni, and J. Ylinen, "Energy-Efficient Elevators for Tall Buildings," in 6th World Congress on Tall Buildings and Urban Habitat, March 2001.

[21] S. M. Plangklang, "Analysis of Energy Consumption and Behavior of Elevator in a Residential Building," in International Electrical Engineering Congress (iEECON), 2017, pp. 1-5.

[5] T. Tukia, S. Uimonen, and M. Lehtonen, "Evaluating the Applicability of Elevators in Frequency Containment Reserves," in 2018 15th International Conference on the European Energy Market (EEM), June 2018, pp. 1-5.

[6] C. F. Nicolas, I. Ayestaran, I. Martinez, and P. Franco, "Model-Based Development of an FPGA Encoder Simulator for Real-Time Testing of Elevator Controllers," in 2016 IEEE 19th International Symposium on Real-Time Distributed Computing (ISORC), May 2016, pp. 53-60.

[7] C. Nicolas, I. Ayestaran, T. Poggi, G. Sagardui, and J. Martin, "A CAN Restbus HiL Elevator Simulator Based on Code Reuse and Device ParaVirtualization," in 2017 IEEE 20th International Symposium on RealTime Distributed Computing (ISORC), May 2017, pp. 117-124.

[8] H.-M. Ryu, S.-J. Kim, S.-K. Sul, T.-S. Kwon, K.-S. Kim, Y.-S. Shim, and K.-R. Seok, "Dynamic Load Simulator for High-Speed Elevator 